\title{
ICONOGRAFÍA FUNERARIA: RESTOS DE TRES LÁPIDAS MEDIEVALES LIGADAS AL CONVENTO DE SAN FRANCISCO DE LA CORUÑA.
}

\author{
por \\ $\mathrm{M}^{\mathrm{a}}$ DOLORES BARRAL RIVADULLA.
}

\begin{abstract}
El descubrimiento de los restos de tres losas funerarias, atribuibles por su emplazamiento al antiguo convento franciscano, contribuye a un mayor conocimiento de la escultura funeraria del medievo coruñés. Los restos localizados corresponden a enterramientos de gentes modestas, en relación con las clases menestrales de la villa - como demuestran las herramientas grabadas en dos de ellas -, que elegirían como lugar de sepelio el cementerio del templo franciscano.

Las lápidas se hallan empotradas en el pavimento de la plaza coruñesa de Carlos I, situada entre la iglesia de la Orden Tercera y el museo militar, en una de las zonas más antiguas de la ciudad. Estos restos no habían sido estudiados hasta el momento probablemente por pasar desapercibidos, ya que dicha plaza es utilizada habitualmente como aparcamiento reservado a autoridades militares cuyas instalaciones se hallan en la misma zona.

El hecho de que las lápidas correspondan, como ya se ha especificado, a un nivel social que podría denominarse bajo, evidencia la relación de los franciscanos con las clases menos poderosas y su popularidad entre las gentes ¿cómo sino éstas elegirán como lugar de inhumación el convento frente a las iglesias parroquiales de la villa?. Por ello, antes de abordar el estudio pormenorizado de los restos hallados ha de plantearse un estado de la cuestión acerca de la presencia de la Orden franciscana en la vida religiosa coruñesa bajomedieval y su importancia a la hora de ser elegidos
\end{abstract}

"CUADERNOS DE ESTUDIOS GALLEGOS", Tomo XLI, Fascículo 106, Santiago 1993-94. 
su iglesia y cementerio como ámbitos de enterramiento ${ }^{1}$. Sin embargo, la insuficiente documentación coruñesa bajomedieval impone plantear el estudio anteriormente propuesto a partir un análisis general del fenómeno de las órdenes mendicantes. Con ello se pretende poder establecer una base sobre la que apoyar con posterioridad los pocos datos documentales que se refieren al convento corunés.

El nacimiento de las órdenes mendicantes surge como respuesta a los grandes problemas con que se enfrenta la iglesia de finales del siglo XII y comienzos del XIII. Ellas darán un nuevo sentido a la religión cristiana, inaugurando una nueva época en la historia del cristianismo que, después de muchos siglos, pasará a convertirse de nuevo en una religión popular ${ }^{2}$.

Los mendicantes alcanzaron el éxito entre las gentes gracias a un nuevo concepto de pastoral fundamentado en un mayor acercamiento al pueblo, como afirma Torres Balbas: « al tipo de monje sedentario y contemplativo, encerrado en su monasterio, sustituyó el del fraile activo, apasionado, incansable, viviendo en medio de la ciudad, en el tumulto de la calle, dedicado a propagar la divina palabra y a remediar las miserias morales y materiales de las agrupaciones humanas» ${ }^{3}$. Las bases de esta nueva pastoral son, entre otras, la predicación en lengua romance, la práctica de obras de caridad $^{4}$, y la defensa de una piedad más personal e interiorizada. Todos estos recursos suscitarán en el fiel una vivencia nueva y particular de su propia religiosidad.

Teniendo en cuenta la popularidad alcanzada por los mendicantes no es difícil imaginar que tras su instalación en villas y ciudades los fieles se encaminasen a solicitar sepultura en sus recintos sagrados. Más aún, es una reacción casi lógica si se tiene en cuenta que en estos momentos ha habido un cambio con respecto a la idea de la muerte y de la salvación

\footnotetext{
${ }^{1}$ La mayoría de estos aspectos han sido analizados en el artículo de la autora: « Os franciscanos e a piedade popular na Baixa Idade Media: O caso do convento coruñes. « en Historia Nova I. Contribución dos xóvenes historiadores de Galicia . Ed. Tórculo, Santiago de Compostela, 1993, p. 151-166.

${ }^{2}$ DUBY, George: Hombres y estructuras de la Edad Media. Ed. Siglo XXI, Madrid, 1978, p. 198.

${ }^{3}$ TORRES BALBAS, Leopoldo: «Arquitectura Gótica» en Ars Hispaniae. Historia Universal del Arte Hispánico. Tomo VII, Ed. Plus Ultra, Madrid, 1952, p. 123

${ }^{4}$ «Como iniciativas de caridad merecen destacarse además de la limosna diaria a los pobres a la puerta de los conventos, el cuidado de los leprosos, tan del gusto de San Francisco, la asistencia a los apestados y las diversas instituciones benéficas como asilos y hospitales». IRIARTE, Lázaro: Historia franciscana. Ed. Asís, Valencia, 1979, p. 171.
} 
eterna, había nacido el Purgatorio.

Este nuevo concepto es difundido a través de los sermones de los mendicantes durante los siglos bajomedievales. La divulgación de la idea de un espacio o estado que permite la salvación de la «segunda muerte», un tercer lugar donde el alma puede purgar sus pecados antes del Juicio, abre una nueva esperanza y, como expresa Jacques Le Goff, consecuentemente «la vida del creyente experimenta un cambio cuando piensa que no se juega todo con la muerte»5.

No sólo cuentan las buenas acciones y la penitencia realizadas en vida sino que el fiel tiene una «segunda oportunidad» tras su muerte. La intercesión de los vivos por los muertos desarrollará un sistema de ayuda a las almas del Purgatorio a base de misas y rezos; pero a ello se unen también las plegarias a determinados santos, entre ellos San Francisco, será uno de los preferidos, porque él mismo, en el momento de su estigmatización, había recibido de Cristo el poder de la salvación de las almas.

¿Sabes tú - dijo Cristo - lo que yo he hecho ?. Te he hecho el don de las llagas, que son señales de mi pasión, para que tú seas mi portaestandarte. Y asi como yo el día de mi muerte bajé al limbo y saqué de él a todas las almas que encontré allí en virtud de estas mis llagas, de la misma manera te concedo que cada año el día de tu muerte, vayas al Purgatorio y saques de él, por la virtud de tus llagas, a todas las almas que encuentres alli de tus tres Ordenes (...) y también las de otros que hayan sido devotos tuyos, y las lleves a la gloria del Paraíso, a fin de que seas conforme a mi como lo has sido en vida» ${ }^{6}$.

Por lo tanto, no es casualidad que ante las nuevas circunstancias el fiel busque el amparo de determinadas órdenes que, como la franciscana, garantizase con sus plegarias la salvación de su alma.

Así pues, las solicitudes de celebración de misas, aniversarios... e incluso las demandas de enterramiento en los conventos son reflejo tanto de

${ }^{5}$ LE GOFF, Jacques: El nacimiento del purgatorio. Taurus Ediciones, Madrid, 1981, p. 9.

${ }^{6}$ Texto de las Florecillas de San Francisco, conclusión III. tomado de GUERRA, Antonio (editor): San Francisco de Asís. Escritos. Biografias. Documentos de la época. Ed. B.A.C., Madrid, 1993, p. 911.

"CUADERNOS DE ESTUDIOS GALLEGOS", Tomo XLI, Fascículo 106, Santiago 1993-94. 
la popularidad de la orden franciscana como de la consideración de ésta como benéfica mediadora cara al Más Allá en un momento en que las inhumaciones en el interior de las iglesias se ha «democratizado» y los mendicantes, desde el siglo XIV, poseen las mismas facultades que las parroquias para aceptar los cuerpos de sus fieles ${ }^{7}$, siempre que se respetasen los derechos de estas últimas.

Una vez esbozado el desarrollo de la importancia del fenómeno mendicante en los siglos bajomedievales, conviene retomar el caso del convento coruñés para con ello establecer en su justa medida la importancia de esta orden en la villa coruñesa.

La instalación de la comunidad franciscana en La Coruña es datada por García Oro en el último tercio del siglo XIII ${ }^{8}$, afirmándose rápidamente su presencia en la villa como demuestra el legado de doscientos sueldos que Teresa Yáñez de Deza les deja en su testamento del año $1262^{9}$. La posición del convento se irá consolidando con el tiempo y en el siglo XV alcanzará un rango importante dentro de las fundaciones que la Orden posee en Galicia.

Los franciscanos se establecen extramuros de la villa coruñesa en un espacio comprendido entre la línea de la costa y la muralla de la ciudad. Este emplazamiento está condicionado por el propio fuero fundacional de la villa ya que por éste los frailes tenían vetada su instalación intramuros:

«Et mando quod non recipiat in suam uillam pro uicinis milites nec fratres praeter fratres de Superado» ${ }^{10}$.

Aunque por esta cláusula los frailes tenían prohibido su emplazamiento en el interior de los muros de la villa; lo cierto es que, por lo general, los mendicantes se instalarán casi siempre en la periferia de las ciudades tan-

\footnotetext{
${ }^{7}$ ORLANDIS, José: «Sobre la elección de sepultura en la España Medieval» en Anuario de Historia del Derecho Español, Tomo XX, Madrid, 1950, p. 5-49 (para nota p. 38-39).

${ }^{8}$ GARCÍA ORO, José (O.F.M.): Francisco de Asís en la España Medieval. (Colección: Monografías de historia eclesiástica. $N^{\circ}$ XVI) C.S.I.C. y Liceo Franciscano, Santiago de Compostela, 1988, p. 121.

${ }^{9}$ Colección Diplomática de Galicia Histórica. Santiago de Compostela, 1901, Documento ${ }^{\circ}$ LIX, p. 265-9.

${ }^{10}$ Documento transcrito en su integridad en GONZÁLEZ GARCÉS, Miguel: Historia de La Coruña. La Edad Media. División de Artes Gráficas de «La Voz de Galicia» S.A., La Coruña, 1988, p. 466-468.
}

"CUADERNOS DE ESTUDIOS GALLEGOS", Tomo XLI, Fascículo 106, Santiago 1993-94. 
to por el menor coste de los terrenos ${ }^{11}$, como para facilitar su labor en contacto con las gentes más pobres, e incluso discriminadas, que habitaban en los arrabales y barrios periféricos de villas y ciudades.

Son pocas las noticias conservadas sobre la influencia de la pastoral franciscana en La Coruña, sin embargo, García Oro supone que la propia instalación de la comunidad en la villa realenga fue favorecida tanto por el episcopado como por el concejo de la villa ${ }^{12}$ que vería en los mendicantes el germen y desarrollo de la propia vida urbana. Los sermones en la iglesia franciscana tenían mucho éxito, e incluso los frailes dedicados a la predicación conocían diversos idiomas o procedían de comunidades de otras naciones. Esta última circunstancia se pone en evidencia en el relato de la visita del peregrino William Wey que, procedente del puerto inglés de Plymouth, arriba a la villa coruñeșa en el año 1456. Antes de partir hacia Santiago «in die corporis Christi habuimus processionem in ecclesia Fratrum Minorum et postea sermonem in eadem ecclesia ad uno anglico bakkulario sacre theologia, cuius thema erat, Ecce ego, vocasti enim me» ${ }^{13}$.

Como expresión de su nueva pastoral ha de tratarse también el ejercicio de obras de caridad. Los franciscanos coruñeses aparecen ligados, según Rey Escariz, a la fundación del hospital de San Antonio, creado por la cofradía de los mareantes para la curación de enfermos contagiosos ${ }^{14}$. Su capacidad para suscitar movimientos espirituales de tipo seglar también aparece documentada en La Coruña medieval, y no sólo a través de la adscripción de cofradías al convento, tema que se retomará más adelante, sino por la dirección que los frailes asumen de una comunidad de beatas terciarias franciscanas que se instalan en torno a la ermita de Santa Bárbara de La Coruña a mediados del siglo $\mathrm{XV}^{15}$. Por último, la fama alcanzada

${ }^{11}$ «Por regla general franciscanos y dominicos estaban situados fuera del núcleo urbano y cerca de las murallas de la ciudad, lugar de terrenos baratos y con facilidad de expansión». BRAUNFELS, Wolfgang: Arquitectura monacal en Occidente. (Breve Biblioteca de Reforma, «Serie Iconológica»), Barral Editores, Barcelona, 1974, p. 190.

${ }^{12}$ GARCÍA ORO, op. cit., p. 121.

${ }^{13}$ GONZÁLEZ GARCÉS, op. cit., p. 642-643.

${ }^{14}$ REY ESCARIZ, Antonio Abelardo: «Hospitales de la gente del mar en La Coruña» en Boletín de la Real Academia Gallega. ( a partir de esta nota citado como B.R.A.G.) Tomo III, La Coruña, 1908-9, p. 170-174 (para nota p. 170-1).

${ }^{15}$ Esta relación es ampliamente estudiada en el artículo de la autora «El convento de Santa Bárbara de La Coruña en el siglo XV: Un caso de terciarias franciscanas en Galicia» en Archivium Franciscanum Historicum Volumen 87, Julio- Diciembre de 1994, fasc. 3 4, Roma (en prensa).

"CUADERNOS DE ESTUDIOS GALLEGOS", Tomo XLI, Fascículo 106, Santiago 1993-94. 
por los franciscanos se materializará en las diversas mandas testamentarias y limosnas con que se favorece a la comunidad y, en la petición de inhumación en su iglesia y cementerio.

La documentación testamentaria coruñesa medieval conservada es escasa, lo cual supone un condicionante importante a la hora de analizar la verdadera dimensión de la adjudicación de mandas y solicitud de enterramiento en el convento franciscano coruñés. Únicamente de las noticias aportadas por los documentos se encuentran un total de once testamentos, de aproximadamente una cuarentena conservados, en los que se cita al convento franciscano. De ellos, en seis se registran donaciones al convento, en cuatro se pide el cumplimiento de misas y, solamente en uno se solicita la inhumación en el convento.

Frente a este silencio documental los restos arqueológicos afirman el carácter preferente de «locus sacro» del templo y cementerio franciscano coruñés.

El número de lápidas medievales conservadas del antiguo convento franciscano se aproxima a la treintena y éstas se hallan localizadas en tres espacios. Un importante número de losas funerarias fueron localizadas recientemente en las excavaciones realizadas en el antiguo emplazamiento del convento franciscano ${ }^{16}$. Las lápidas halladas en esta ubicación completan un hipotético catálogo al que se unirían las depositadas en el museo arqueológico local y las emplazadas en el pavimento de la plaza de Carlos I.

La excavación de los cimientos de la antigua ubicación de la iglesia denota la existencia de un espacio preferente de inhumación en el interior de ésta mientras que en su cementerio se enterrarían aquellos cuyos medios no eran suficientes para costearse una sepultura en el interior del templo pero que, de alguna manera, buscan la protección de la Orden inhumándose en el exterior de la iglesia. A esta última categoría pertenecerían los restos hallados en la plaza de Carlos I ya que corresponden, como se ha mencionado, a las clases menestrales de la villa. (Figura 1).

${ }^{16}$ Estas lápidas fueron halladas en la excavación llevada a cabo durante el año 1991, bajo la dirección del arqueólogo Xoan Luis Vázquez Gómez. Los resultados provisionales de esta excavación no han visto aún la luz debido a que el proceso de la misma se halla interrumpido. Sin embargo, agradezco al director de la excavación las facilidades que me fueron dadas para conocer los detalles de la misma, vitales a la hora de elaborar este trabajo.

"CUADERNOS DE ESTUDIOS GALLEGOS", Tomo XLI, Fascículo 106, Santiago 1993-94. 


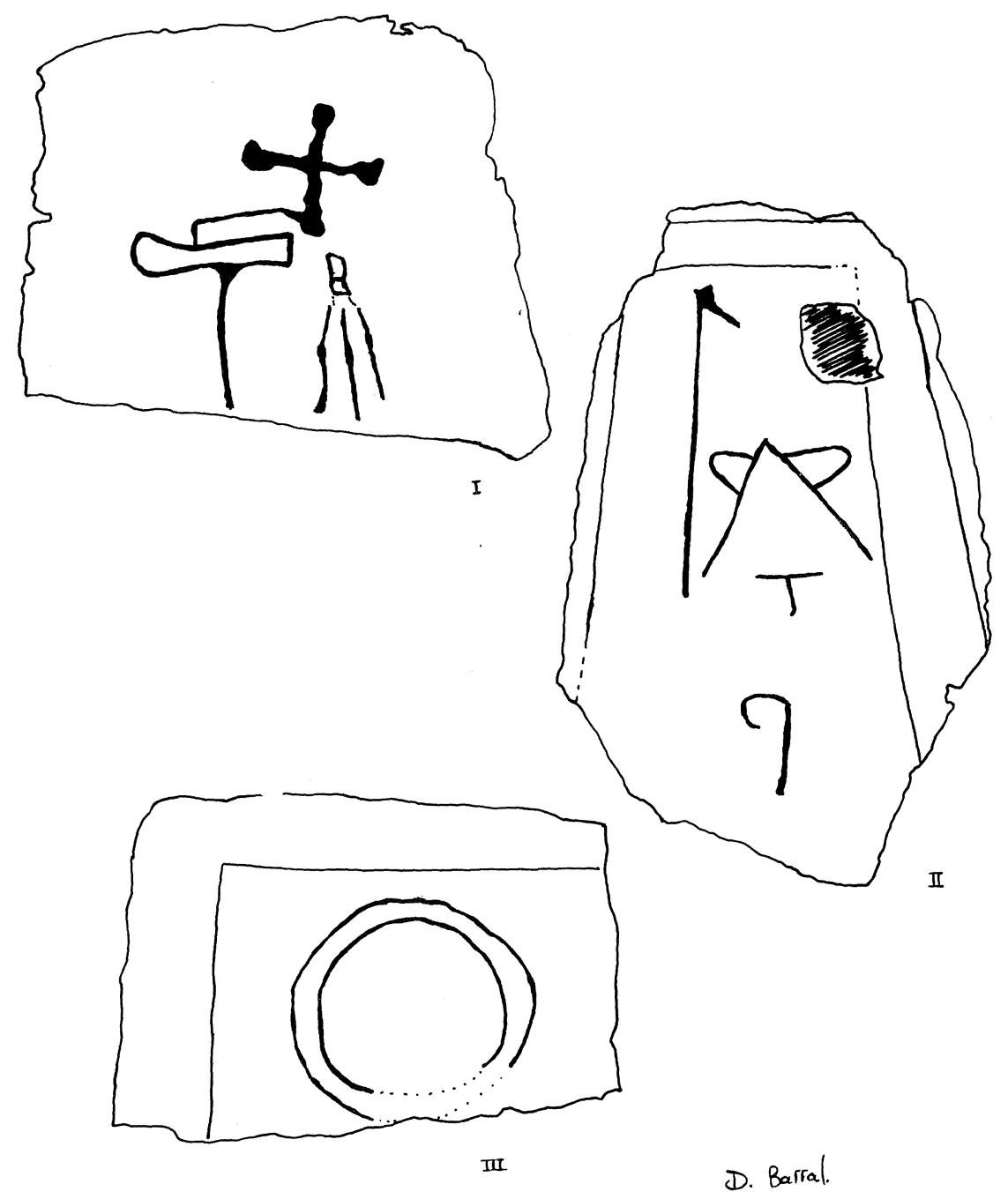

Figura $n^{\circ} 1$ 
Los tres restos conservados pertenecen al tipo tumular que Panofsky define como «tomb slab» ${ }^{17}$, es decir, lápidas bajo las cuales el cuerpo se alojaría directamente en la tierra, integrándose la sepultura en el suelo. Prototipo derivado, según el mismo autor, de la tradición norteafricana de cubrir el pavimento de las iglesias con mosaicos funerarios ${ }^{18}$. Sin embargo, esta teoría es matizada por Aries quien afirma que este tipo de tumba, siempre identificada por un grabado, es un modelo propio del medievo y fruto de una mentalidad social que por un lado, pretende la humildad al confiar el cuerpo a la tierra, y por otro, apunta la necesidad de dejar testimonio a la posteridad de la individualidad del finado ${ }^{19}$.

Según los símbolos grabados en las tres lápidas objeto de este estudio, éstas se corresponderían, dentro de una hipotética clasificación de las lápidas del convento, a dos grupos distintos. Por un lado estarían las lápidas cuyos motivos aparecen relacionados con las distintas profesiones u oficios (Lápidas I y II) y, por otro, las laudas ornadas con motivos emblemáticos con la complementareidad del cordón franciscano (Lápida III).

Al primer grupo de laudas pertenecen también varias de las depositadas en el museo arqueológico local, su conservación pone de relieve la relación de los franciscanos con el mundo de los trabajadores y de las cofradías. Si hubiera de añadirse alguna otra característica a los efectos del franciscanismo en la mentalidad de las gentes medievales, indudablemente esta podría ser su labor pastoral orientada a la revalorización del mundo del trabajo. Frente a la tradición que postulaba un cierto rechazo a este mundo - de hecho los «laboratores» ocupan el tercer estamento en la división social de comienzos del medievo - los franciscanos abogan por una defensa de éste. El propio San Francisco, en su regla segunda a los hermanos menores, aconsejaba: «aquellos hermanos a quienes ha dado el Señor la gracia del trabajo, trabajen fiel y devotamente, de forma tal, que, evitando el ocio, que es enemigo del alma, no apaguen el espíritu de la santa oración y devoción, a cuyo servicio están las demás cosas temporales $\rangle^{20}$.

${ }^{17}$ PANOFSKY, Erwin: Tomb sculpture. Its changing aspects from Ancient Egypt to Bernini. London, 1964, p. 47.

${ }^{18}$ Ibidem.

${ }^{19}$ ARIES, Philippe: El hombre ante la muerte. (Colección ensayistas $N^{\circ} 229$. Serie Maior) Taurus Ediciones S.A., Madrid, 1984, p. 202.

${ }^{20}$ GUERRA, op. cit., p. 112-113.

"CUADERNOS DE ESTUDIOS GALLEGOS", Tomo XLI, Fascículo 106, Santiago 1993-94. 
Así pues, el trabajo es reivindicado por los mendicantes, adquiriendo éste una dimensión más racional donde el sentido redentor que le atribuía la iglesia tradicional queda mediatizado. Con esta nueva orientación no es extraño encontrar que determinadas cofradías se vinculen al convento franciscano.

Poco se puede aportar al conocimiento de las cofradías medievales coruñesas ya que el análisis de las mismas está sin efectuar. Sin embargo, a través de estas líneas, puede trazarse un pequeño esquema de su funcionamiento. Los artesanos coruñeses aparecen citados en los primeros documentos medievales conservados sobre la ciudad - figurando como testigos en pleitos, en actas del concejo...- y el desarrollo de su actividad aparece ligado al propio crecimiento de la villa. El comercio exterior y abastecimiento de la propia población fomentarán su actividad, sobre todo, en los siglos XIV y XV. La unión del artesanado coruñés en gremios parece temprana, aunque, siguiendo otros ejemplos gallegos, es posible que su grado de desarrollo fuese mínimo y más que funcionar como tales su asociacionismo se vinculase más a la forma de cofradías. Éstas, cuentan con ordenanzas propias, en las que se estipulan las órdenes necesarias sobre la fabricación y venta de sus productos. Las cofradías, colocadas bajo la advocación de un patrón, son, al mismo tiempo, la representación de la devoción particular. Casi familias, dentro de sus estatutos y reglas se contienen algunas normas destinadas a la práctica religiosa: rezan en común; asisten a los velatorios, enterramiento y funerales de uno de los suyos; se ayudan en las desgracias, protegen sus negocios ante competencias desleales... La mayoría de las cofradías coinciden con un gremio, o varios que se dedican a actividades dependientes unas de otras. En La Coruña medieval se desarrollan una serie de gremios importantes, cada uno de los cuales aparece ligado a una cofradía que tiene su sede en alguna de las iglesias o conventos de la ciudad. Así, los sastres, pertenecen a la cofradía de San Miguel, cuya sede está en la iglesia de Santiago; los zapateros a la cofradía de Santa María, cuyo altar está en la iglesia de Santa María junto con el de los herreros, cerrajeros y caldereros que forman parte de la del Corpus Cristi. Respecto a las cofradías vinculadas al convento coruñés han de extrapolarse los datos que proporciona la documentación de los siglos XVI y XVII ya que no hay datos medievales que puedan situar la instalación de estas cofradías en el convento franciscano, las cofradías mencionadas son: la de Nuestra Señora de la Humildad, cofradía de la Audiencia, cofradía del hospital de San Andrés, de la Vera Cruz, 
del Espíritu Santo, de los carpinteros y de la Inmaculada Concepción ${ }^{21}$.

El segundo grupo de las laudas, es decir, aquellas ornadas con motivos emblemáticos con la complementareidad del cordón franciscano pone, como en el caso anterior, de relieve la influencia de la pastoral franciscana entre las gentes. Quienes, además de inhumarse en su recinto sacro, exornan su lápidas con el motivo del cordón franciscano aludiendo probablemente al carácter benéfico de la Orden a la que encomiendan su cuerpo. Conocida es la predilección de algunos fieles de inhumarse con el hábito de una determinada Orden, por ello la aparición del cordón guarda el doble significado de signo de devoción al Santo y su Orden y el «compromiso» por parte del fiel del seguimiento de los postulados de la Orden Franciscana, reflejados en los tres nudos que normalmente se destacan en el cordón representado sobre las lápidas. Se buscaba pues la salvación del alma sin olvidar que, como se ha mencionado anteriormente, Cristo había prometido a San Francisco que pudiese salvar del Purgatorio las almas « de otros que hayan sido devotos tuyos, y las lleves a la gloria del Paraiso» ${ }^{22}$.

Una vez anotada la filiación tipológica de las lápidas es necesario establecer la cronología de las mismas. Los tres ejemplos conservados muestran dificultades en su datación ya que se carece de datos complementarios, como los documentales o epigráficos, que aporten una cronología exacta. A falta de datos concretos la datación de las mismas podría enmarcarse, de una manera global entre los siglos XIV y XVI. El primer siglo de referencia es tomado en función de que hasta ese momento no comenzaría la construcción del recinto conventual franciscano coruñés. Como propone Bonelli, los asentamientos primigenios de las comunidades mendicantes fueron en ermitas o capillas o pequeñas iglesias para, en una segunda fase, comenzar a construir sus propios conventos ${ }^{23}$. La imposición de un extremo cronológico en el siglo XVI se basa en las investigaciones desarrolladas sobre las laudas profesionales de Santa María a Nova

${ }^{21}$ RODRÍGUEZ PAZOS, Manuel: «Cofradías piadosas y capellanías castrenses en el convento de San Francisco de La Coruña (Siglos XVI-XVII)» en B.R.A.G. T. XXIV, La Coruña, 1944, p. 423-437.

${ }^{22}$ Véase nota $n^{\circ} 6$.

${ }^{23}$ BONELLI, Renato: «Nuovi sviluppi di ricerca sull'edilizia mendicanti» en Gli ordini mendicanti e la città. Aspetti architettonici, sociali e politici. Guernni Studio, Milano, 1990, p. 15-26 (para nota p. 24).

"CUADERNOS DE ESTUDIOS GALLEGOS", Tomo XLI, Fascículo 106, Santiago 1993-94. 
de Noia por Torres Reino ${ }^{24}$.

El estudio de los restos se aborda desde el punto de vista de la arqueología y de la historia del arte, aportando tanto los datos esenciales de medidas y material de las lápidas como los complementarios que derivan del estudio iconográfico y comparativo de las mismas.

\section{LAPIDA I. (Figura ${ }^{\circ} 2$ )}

Medidas:

Largo izquierdo: $0.53 \mathrm{~m}$. Largo derecho: $0.45 \mathrm{~m}$. Ancho Superior: $0.73 \mathrm{~m}$. Ancho Inferior: $0.70 \mathrm{~m}$.

Estado de conservación:

Malo. La lauda aparece incompleta y muy erosionada conservándose únicamente la parte superior de la misma.

Observaciones y descripción:

El fragmento de lauda conservado, realizado en granito, se ha de relacionar directamente con laudas de tipo profesional y, en concreto, con modelos alusivos al oficio de carpintero de ribera.

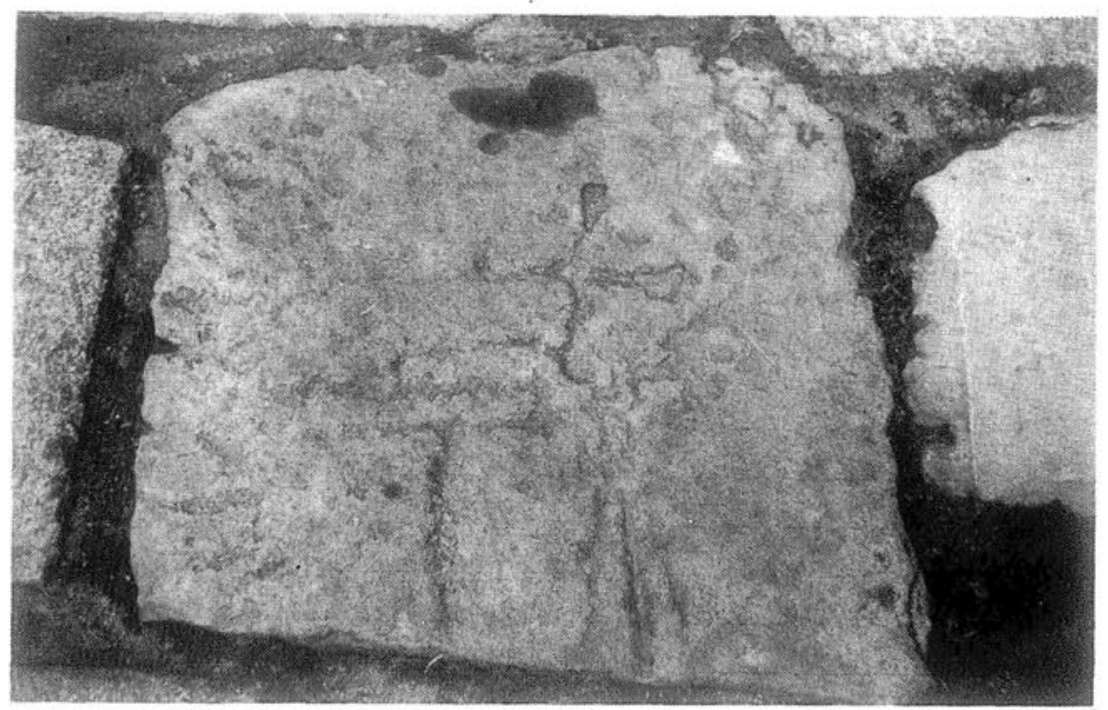

Figura $n^{\circ} 2$ : Lápida I

${ }^{24}$ TORRES REINO, Xosé María: «A necrópole de Santa María de Noia. O estado da cuestión» Apéndice a la reedición del libro de Alvaro de las Casas O cemiterio de Santa Maria de Noia. (Colección Seitura) Editorial Sementeira, Noia, 1990.

"CUADERNOS DE ESTUDIOS GALLEGOS", Tomo XLI, Fascículo 106, Santiago 1993-94. 
Ejemplos de este tipo se localizan en el cementerio de Santa María «a Nova» (Noia), e incluso algunos se conservan en el propio museo arqueológico e histórico de La Coruña. Es el caso de la lauda de María de Noia, hallada en el año $1912^{25}$ en el transcurso de unas reformas realizadas en la calle de San Francisco, cercana a la plaza donde se sitúa el fragmento de lauda a describir. (Ilustración nº 3 ). Esta lápida, cuya datación corresponde al año 1442, aparece exornada con diferentes instrumentos y símbolos alusivos a la profesión del difunto, en ella aparecen: el hacha, la escuadra, dos compases y, a ambos lados del mango del hacha, el sol y la luna. La aparición de un epígrafe junto con los instrumentos profesionales ya descritos, aluden al enterramiento de una mujer, probablemente esposa de un carpintero de ribera. Así pues, la difunta asumirá en el momento de su muerte los signos distintivos de la profesión de su marido.

El ejemplo localizado en la plaza de Carlos I es sin duda también el de un carpintero de ribera, la repetición de las herramientas: hacha, escuadra y compás lo hace paralelo al ejemplo conservado en el museo arqueológico local, sin embargo, la erosión a que ha sido sometida la lápida impide distinguir si ésta tuvo en algún momento epígrafe, con lo cual se evidencia la imposibilidad de asignarle una datación exacta. Así, únicamente se puede concretar que se trata de la lauda funeraria de un artesano, el cual accede a la fama póstuma a través de la individualización de su enterramiento mediante los símbolos distintivos de su oficio.

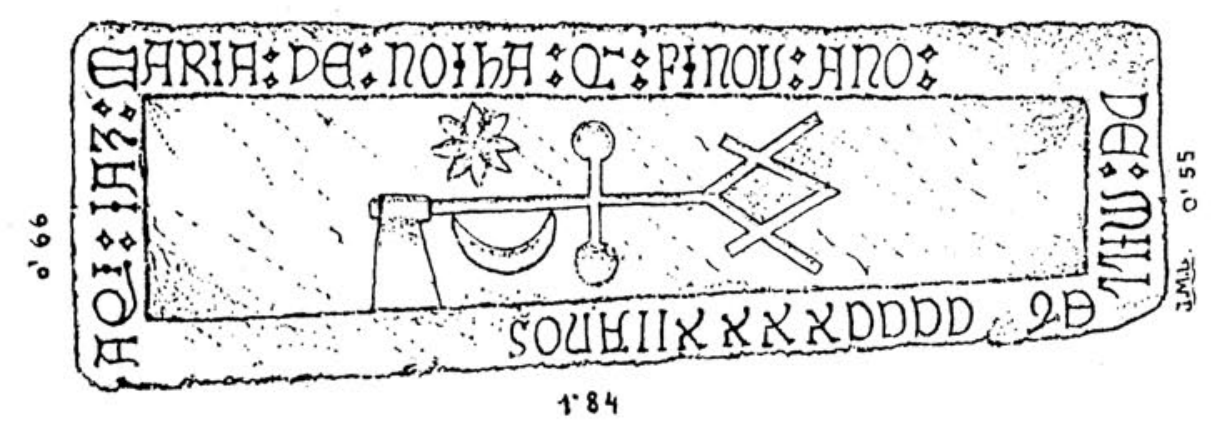

Figura $n^{\circ}$ 3: Lauda funeraria de María de Noia (según Martínez Luengo).

${ }^{25}$ GONZAGA, Fr.: «Hallazgos arqueológicos en La Coruña» en B.R.A.G. Tomo VI, La Coruña, 1912-13, p. 84-86.

"CUADERNOS DE ESTUDiOS GALLEGOS", Tomo XLI, Fascículo 106, Santiago 1993-94. 
La profesión de carpintero ligado a la construcción naval tuvo gran desarrollo en la villa coruñesa en época medieval. Así por ejemplo en el año 1507 , ante la gran demanda de mano de obra para la construcción de barcos surgida en Pontevedra, llegará a esta villa desde La Coruña una cuadrilla integrada por quince carpinteros bajo la dirección de Roy de Sequeiros «carpentero e mestre de fazer naos» ${ }^{26}$.

\section{LAPIDA II. (Figura $\mathrm{n}^{\circ}$ 4)}

Medidas:

Largo izquierdo: $1.05 \mathrm{~m}$. Largo derecho: $1.39 \mathrm{~m}$. Ancho Superior: $0.41 \mathrm{~m}$. Ancho Inferior: $0.32 \mathrm{~m}$.

Estado de conservación:

Malo, la lauda aparece fragmentada y bastante erosionada aunque la parte central de la misma se conserva prácticamente intacta.

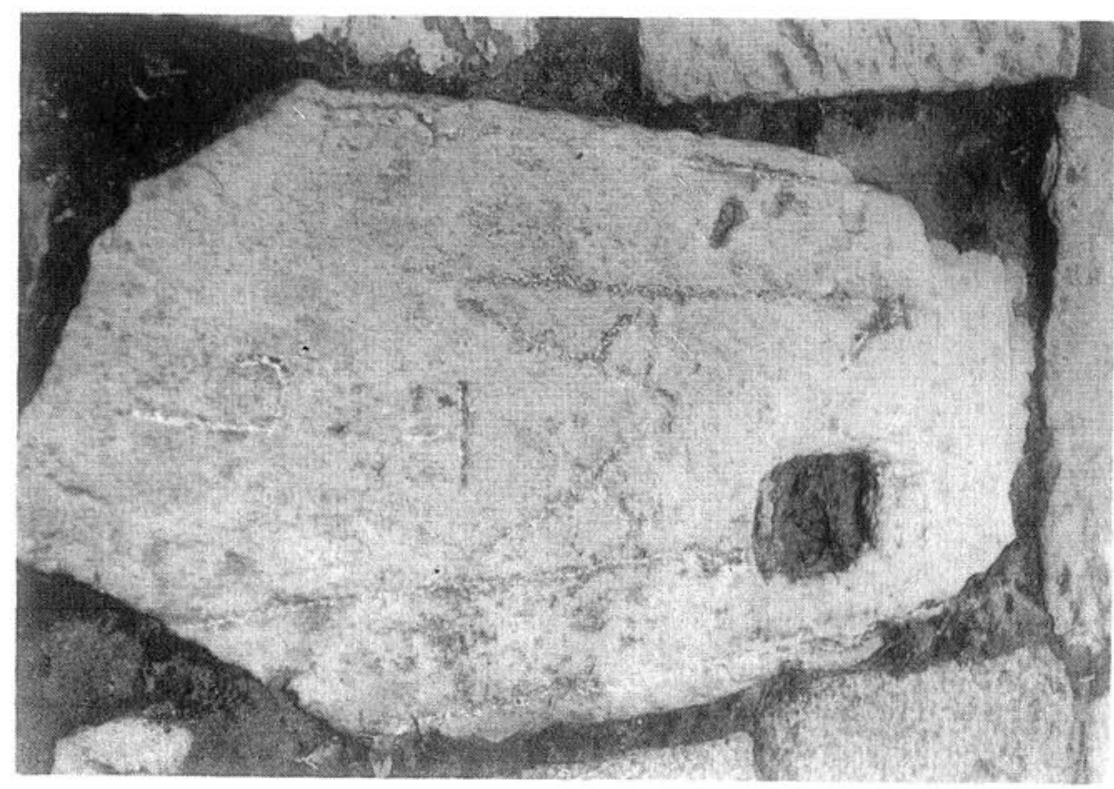

Figura $n^{\circ} 4$ : Lápida II

${ }^{26}$ ARMAS CASTRO, José A.: Pontevedra en los siglos XII a XV. Configuración y desarrollo de una villa marinera en la Galicia Medieval. Fundación Pedro Barrié de La Maza, Pontevedra, 1992, p. 165.

"CUADERNOS DE ESTUDIOS GALLEGOS", Tomo XLI, Fascículo 106, Santiago 1993-94. 
Observaciones y descripción:

Realizada en granito, la lauda muestra entre sus motivos centrales: una « $\mathrm{T}$ », una « $\mathrm{P}$ » invertida, un compás y un símbolo similar a un arpón, estos dos últimos instrumentos remiten, de nuevo, a la vida marinera y a los oficios desarrollados en su entorno, pudiendo aludirse de nuevo a la profesión de carpintero de ribera.

Frente a la lauda anterior, esta originariamente debió portar epígrafe, como demuestra la presencia del listel que recorre la lápida. En la actualidad es imposible distinguir ningún detalle de lo que pudo contener dicha inscripción ya que el grado de erosión de la misma es muy alto.

\section{LAPIDA N ${ }^{\circ}$ III. (Figura ${ }^{\circ}$ 5)}

Medidas:

Largo izquierdo: $0.56 \mathrm{~m}$. Largo derecho: $0.65 \mathrm{~m}$. Ancho Superior: $0.70 \mathrm{~m}$. Ancho Inferior: $0.73 \mathrm{~m}$.

Estado de conservación:

Malo, sólo se conserva un pequeño fragmento correspondiente a la esquina superior izquierda de la lauda original.

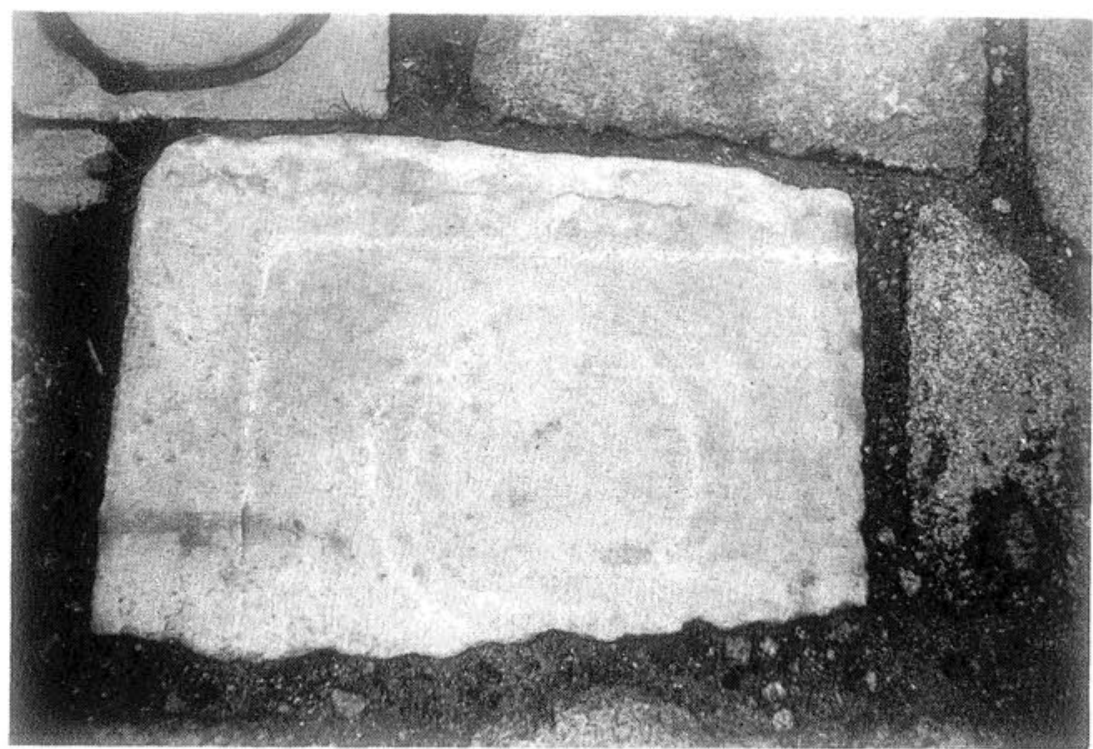

Figura $n^{\circ} 5$ : Lápida III.

"CUADERNOS DE ESTUDIOS GALLEGOS", Tomo XLI, Fascículo 106, Santiago 1993-94. 
Observaciones y descripción:

Realizada en granito y grabada en bajorrelieve, el fragmento conservado presenta la parte superior de la representación de un cordón franciscano. Esta fracción de lauda remite de nuevo a ejemplos existentes en el cementerio de Santa María «a Nova» y a otros coruñeses, tanto rescatados en las excavaciones realizadas en el antiguo emplazamiento de la iglesia de San Francisco de la Coruña como a algunos depositados en el museo arqueológico local, por ejemplo la lauda de María Rodríguez. (Figura ${ }^{\circ}$ 6)

Esta lápida está realiza en granito y grabada en bajorrelieve, al igual que la lápida de la plaza de Carlos I presenta como motivo central el cordón franciscano, pero en su centro se encuentra labrado un símbolo de tipo heráldico, el lobo de los Moscoso ${ }^{27}$. Complementa a estos motivos un epígrafe que alude a la identidad del difunto y fija la fecha de su óbito en el año 1417: «AQ(U)I : IAZ : MARIA : RODRIGUES :.... O/......./ :M... : M : CCCCXVII»

A través de este ejemplo se puede conjeturar a cerca de la apariencia completa del fragmento de lauda hallado. Ésta aparecería decorada con el motivo central del cordón franciscano con sus correspondientes nudos y, como en la lauda anterior, originariamente portaría epígrafe, la presencia del listel y de algunas letras, hoy apenas insinuadas, lo confirman.

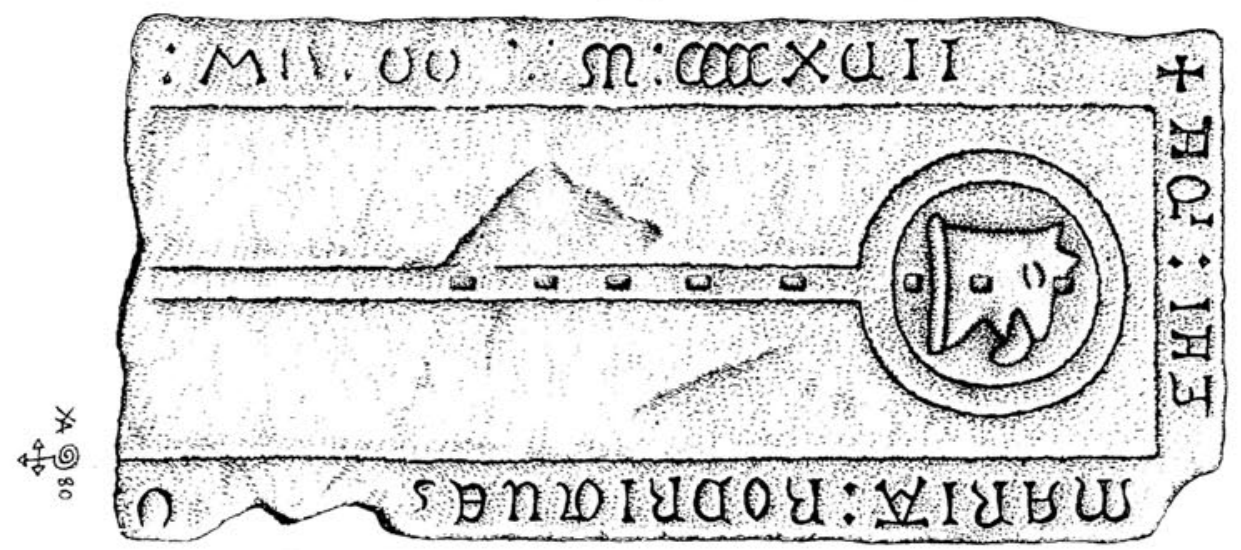

Figura $n^{\circ}$ 6: Lauda de María Rodríguez (según García G. Ledo).

${ }^{27}$ GARCÍA GONZÁLEZ-LEDO, Xosé Antón y RIVADULLA PORTA Xosé Enrique: «A colección heráldica do museu arqueolóxico e histórico da Coruña» en Brigantium $\mathrm{n}^{\circ} 3$, La Coruña, 1982, p. 193-224 (para nota p. 198).

"CUADERNOS DE ESTUdiOS GALLEGOS", Tomo XLI, Fascículo 106, Santiago 1993-94. 